\title{
Optic Disc Edema
}

National Cancer Institute

\section{Source}

National Cancer Institute. Optic Disc Edema. NCI Thesaurus. Code C118872.

Swelling of the optic disc in the absence of increased intracranial pressure. 